\title{
Inserção dos Turismólogos Brasileiros no Mercado de Trabalho'
}

\author{
Luana Alexandre Silva ${ }^{a}$ \\ Luciana Araújo de Holandab \\ Sérgio Rodrigues Lealc
}

\section{Resumo}

Pela elevada capacidade de gerar empregos, o turismo esteve sempre presente no discurso governamental como vetor de desenvolvimento econômico no país. Entretanto, apesar da crescente demanda turística e do consequente incentivo aos programas de formação profissional para a atividade turística, os turismólogos enfrentam dificuldades em inserir-se no mercado de trabalho. 0 desequilíbrio entre oferta e demanda de mão de obra qualificada, o desconhecimento dos empregadores sobre em que consiste um curso superior em turismo e a formação superior desalinhada com as necessidades das empresas turísticas são alguns dos problemas que marcam o cenário do turismo no Brasil. Diante dessa problemática, o presente estudo investigou a inserção dos turismólogos formados no Brasil no mercado de trabalho por meio de uma survey on-line com 322 respondentes de diversas regiões do país. Os respondentes, predominantemente, do gênero feminino, com idade entre 20 e 30 anos, nível de graduação e domínio de inglês ou espanhol, atuam, principalmente, na docência e agenciamento de viagens e recebem uma remuneração mensal de um a três salários mínimos. Os pesquisados qualificam o curso superior de turismo como importante ou muito importante para a prática profissional e se consideram satisfeitos ou pouco satisfeitos com sua atuação no mercado de trabalho.

Palavras-chave: Bacharéis em turismo; Mercado de trabalho; Absorção; Brasil.

\section{Abstract \\ Insertion of Tourism Graduates in the Brazilian Job Market}

The tourist activity has always been present in the speech of managers and government leaders as an important ally to national economic development due to its capacity to generate employment. However, despite the growing demand for tourism and the consequent incentive to training programs in the area, tourism graduates have struggled entering the job market. The imbalance between supply and demand of skilled labor, employers' lack of knowledge of what a tourism program is, and higher education misaligned with the needs of tourism businesses are examples of problems that shaped the evolution of tourism in Brazil. Given these problems, this study aims to investigate the insertion of Brazilian tourism graduates in the job market. A quantitative study through an online survey was conducted and resulted in 322 complete questionnaires from respondents from different regions of Brazil. The respondents' profile is

1. Trabalho apresentado no Fórum Abratur 17, realizado em Recife, PE, de 7 a 9 de junho de 2017. Foi escolhido como um dos melhores trabalhos do evento.

a. Doutora em Administração pela Universidade Federal de Pernambuco, Recife, Pernambuco, Brasil. E-mail: luanaalsilva@gmail.com

b. Doutora em Administração pela Universidade Federal de Pernambuco. Professora do curso de graduação em Turismo e de mestrado em Hotelaria e Turismo na Universidade Federal de Pernambuco, Recife, Pernambuco, Brasil. E-mail: luciana.holanda@ufpe.br

c. Possui pós-doutorado em Estágio Pós-Doutoral pela Breda University of Applied Sciences, Breda, Brabante do Norte, Holanda. Professor do curso de graduação em Turismo e de mestrado em Hotelaria em Turismo na Universidade Federal de Pernambuco, Recife, Pernambuco, Brasil. E-mail: sergio.rleal@ufpe.br 
mainly composed of females, aged between 20 and 30 years, with an undergraduate degree and English and/or Spanish fluency. The main areas of the investigated tourism graduates are teaching and working in travel agencies, and the monthly wage of the majority is about one to three minimum wages (approximately US $\$ 295$ to US $\$ 885$ in October 2017). The respondents consider higher education in tourism as important or very important for professional practice and they see their professional position as either satisfactory or partially satisfactory.

Keywords: Tourism graduates; Labour market; Absorption; Brazil.

\section{Resumen}

\section{Inserción de los turismólogos en el mercado de trabajo brasileño}

Por su gran capacidad de generar puestos de trabajo, la actividad turística siempre estuvo presente en el discurso de los gerentes y líderes del poder público como un importante aliado para el desarrollo económico en el país. Sin embargo, a pesar de la creciente demanda de turismo y el consiguiente fomento de programas de formación profesional para el área, los turismólogos han enfrentado dificultades en relación con su inserción en el mercado laboral. El desequilibrio entre la oferta y la demanda de mano de obra especializada, y la educación superior distante de las necesidades de las empresas turísticas son los problemas que marcan el escenario del turismo en Brasil. Ante este problema, el presente estudio se propuso investigar la inserción de turismólogos formados en Brasil en el mercado laboral. Para tanto, se llevó a cabo una encuesta electrónica donde se obtuvo una muestra de 322 participantes de diversas regiones del país. Los encuestados, en su mayoría mujeres entre 20 y 30 años de edad, poseen el nivel de grado y dominio de inglés y/o español, actúan, principalmente, en los segmentos de enseñanza y agencia de viajes, reciben un pago mensual entre uno y tres sueldos mínimos, califican el curso superior de turismo como muy importante o importante para la práctica profesional y se consideran satisfechos o algo satisfechos con su desempeño en el mercado laboral.

Palabras clave: Licenciados en turismo; Mercado de trabajo; Absorción; Brasil.

\section{INTRODUÇÃO}

A atividade turística esteve sempre presente no discurso governamental como um importante aliado em prol do desenvolvimento de um país. Em termos econômicos e sociais, a importância do turismo é cada vez mais reconhecida por sua repercussão na balança de pagamentos, geração de divisas, geração de empregos, efeito multiplicador, distribuição de renda e elevação das condições de vida das comunidades receptoras.

Em comparação com outros setores econômicos intensivos em capital, o turismo é altamente intensivo em mão de obra e possui elevada capacidade de geração de empregos em diversos níveis de qualificação (Ladkin, 2008; Matias \& Costa, 2010; Organização Internacional do Trabalho [OIT], 2011). Em 2016, o turismo gerou 292 milhões de empregos, correspondendo a 1 em cada 10 empregos da economia global (World Travel \& Tourism Council [WTTC], 2017).

No Brasil, de 2003 a 2009, o número de ocupações nas Atividades Características do Turismo (ACT) representou 9,9\% do setor de serviços e 6,1\% de toda a economia do país, sendo as atividades recreativas, culturais e desportivas, e os serviços de alimentação os principais responsáveis por esse crescimento (Instituto Brasileiro de Geografia e Estatística [IBGE], 2012). Em 2016, o turismo contribuiu com 8,4 milhões de trabalhos diretos, indiretos e induzidos, principalmente nos setores de hospedagem, transporte e agenciamento de viagens (WTTC, 2017).

0 reconhecimento do grande potencial gerador de empregos do turismo e da necessidade de mão de obra qualificada para atuar na atividade turística legitimaram 
e direcionaram a formação de profissionais na área (Sogayar \& Rejowski, 2011), levando as Instituições de Ensino Superior (IES) a criarem cursos superiores em turismo. No Brasil, em acréscimo ao contexto mundial de desenvolvimento da atividade turística, as condições políticas, econômicas e sociais do país (como os incentivos governamentais, o "milagre econômico" e a ascensão da classe média) propiciaram o surgimento desses cursos, oferecidos inicialmente por IES privadas.

Ansarah (2002) divide a cronologia dos cursos superiores de turismo no Brasil em quatro fases. A primeira caracteriza-se pelo surgimento dos primeiros cursos na década de 1970; a segunda pela estagnação dos cursos devido aos problemas econômicos do país nos anos 1980; a terceira pela valorização e grande expansão dos cursos na década de 1990 e a quarta e última, pelo equilíbrio entre qualidade e quantidade, através do aumento de ofertas diferenciadas em áreas como eventos e lazer, a partir de 2000. Uma década após a publicação da obra de Ansarah (2002), Leal, Panosso Netto e Trigo (2012) expandiram e atualizaram a cronologia dos cursos superiores de turismo no país, sugerindo uma quinta fase, caracterizada pela internacionalização da pesquisa e dos cursos da área.

Entre a quarta e quinta fase de desenvolvimento, mais especificamente na segunda metade da década de 2000, os cursos superiores de turismo no Brasil vivenciaram dificuldades, exemplificadas na redução do número de alunos e no fechamento de alguns cursos em instituições privadas. Essas dificuldades refletiram problemas de sobrevivência dos cursos ou acomodações do mercado, como elencou Carvalho (2008), podendo também estarem relacionadas aos problemas de absorção da mão de obra pelo mercado de trabalho, conforme Silveira, Medaglia e Gândara (2012, p. 11) ressaltam.

Em quase cinco décadas de oferta de graduação em turismo, a Associação Brasileira de Turismólogos e Profissionais do Turismo (ABBTUR, 2013) estima que há cerca de 200 mil turismólogos formados no país, dos quais 58,5\% atuam no campo do turismo. Ou seja, quase a metade dos turismólogos não atua na área de formação. Esses dados são corroborados nas discussões em eventos científicos de turismo que evidenciam as dificuldades enfrentadas pelos turismólogos em sua inserção no mercado de trabalho. Barretto, Tamanini e Silva (2004) verificaram que os profissionais formados pela Universidade do Vale do Itajaí (Univali) não foram absorvidos pelo mercado turístico. Comparando com dados internacionais, na Espanha, 51,7\% dos diplomados em turismo trabalham no campo turístico enquanto $20,8 \%$ atuam em outra atividade econômica (Agencia Nacional de Evaluación de la Calidad y Acreditación, 2005). Já na Austrália apenas 5\% dos postos estavam ocupados por bacharéis em turismo e no Reino Unido, apenas 10\% (Barretto et al., 2004).

Os estudos já desenvolvidos sobre a absorção dos turismólogos pelo mercado de trabalho apontam diversos fatores que podem estar relacionados a essa problemática, como: as características do mercado de trabalho, o desequilíbrio entre oferta e demanda de mão de obra qualificada, e a formação profissional desalinhada com as necessidades das empresas turísticas (Arbache, 2001; Barretto et al., 2004; Fonseca \& Petit, 2002; Lima \& Silva, 2007; Silveira et al., 2012; Sogayar \& Rejowski, 2011).

Decorrente da quantidade de profissionais lançados ao mercado, devido à explosão dos cursos de turismo, uma profissão que era praticamente desconhecida tornou-se massificada e o número de profissionais no mercado passou a ser maior do que a quantidade de vagas oferecidas, fazendo com que muitos formados ocupassem posições de trabalho em cargos operacionais, que pouco 
exigem de sua formação e que desvalorizam esses profissionais que tiveram de atuar com salários incompatíveis com as suas expectativas (Silveira et al., 2012; Sogayar \& Rejowski, 2011).

Outro aspecto é a falta de adequação da formação turística às necessidades do setor turístico. A Organização Mundial do Turismo (OMT) preconiza que a educação e formação turísticas devem contribuir para a competitividade do setor e, para isso, devem realmente responder às necessidades de capital humano das organizações turísticas. Porém, para Ansarah (2002), a proposta pedagógica da maioria dos cursos superiores parece inadequada, formando profissionais que não irão atender às reais necessidades de mercado. Kong (2015) ressalta que os empregadores se queixam que os graduados em turismo e hotelaria não são bem preparados e que lhes falta conhecimentos, habilidades e atitudes requeridas pelo mercado turístico. Um dilema que requer coordenação entre o currículo dos cursos e as necessidades mercadológicas (Kong, 2015).

Tendo em vista que a qualificação de pessoas para o turismo e sua inserção no mercado de trabalho são fatores primordiais para o desenvolvimento estruturado da atividade turística (Mota \& Anjos, 2012), o presente estudo buscou analisar a atuação dos bacharéis em turismo formados no país, identificando os segmentos onde trabalham, o perfil desses profissionais, a remuneração mensal recebida e a satisfação destes em relação à sua atuação no mercado de trabalho.

\section{MERCADO DE TRABALHO NO TURISMO NO BRASIL}

O turismo é caracterizado pela amplitude e diversidade de possibilidades de atuação profissional. 0 mercado turístico é composto por um agregado de organizações, tais como meios de hospedagens, agências de viagens, operadoras turísticas, companhias aéreas, transportadoras turísticas, organizadores de eventos, restaurantes, empresas de entretenimento e lazer, comércio de artesanato, dentre outras, que participam da elaboração, organização e comercialização dos produtos turísticos. Para além da venda e prestação de serviços, há também as entidades de classe e os órgãos oficiais que planejam, financiam e regulam a atividade turística, sendo também provedores de postos de trabalho.

Todas essas organizações formam o mercado de trabalho no turismo, o qual compreende as vagas para atuar de forma remunerada em alguma das atividades turísticas. Esse mercado demonstra características semelhantes em vários países como é o caso da grande porcentagem de trabalhadores temporários, a pouca presença de mulheres em cargos de maior responsabilidade, a presença marcante de jovens com baixa qualificação, a baixa remuneração e a extensiva carga horária semanal (Barretto et al., 2004).

As condições de trabalho na atividade turística, como aponta Costa (2008, p. 120), seguem a tendência vigente no mundo do trabalho, com especificidades do setor. Em função da sazonalidade inerente à atividade turística, registra-se um elevado percentual de trabalhadores em tempo parcial, temporários, esporádicos e ocasionais (Barretto et al., 2004; Coelho \& Sakowski, 2014; Cunha, 1997; OMT, 1997). A oferta de emprego no turismo se enquadra, geralmente, nas modalidades de tempo integral, meio expediente, temporário, ocasional e sazonal, e frequentemente cruza as tênues fronteiras entre a economia informal e formal (OIT, 2011). 
Os empregados no turismo possuem, em sua maioria, baixa escolaridade (Coelho \& Sakowski, 2014; Fonseca \& Petit, 2002) e baixa qualificação, sendo, muitas vezes, procedentes de outros setores econômicos sem nenhuma formação específica em turismo (OMT, 1997). No Brasil, os dados parecem confirmar esse cenário. A escolaridade dos empregados no turismo é inferior à da média da economia brasileira; apenas $7 \%$ dos ocupados formais do turismo no Brasil possuem nível superior, 34\% têm nível fundamental, enquanto os demais possuem ensino médio ou nível superior incompleto (Coelho \& Sakowski, 2014). Para Oganauskas, Gomes e Andrukiu (2012), a área de turismo é uma das poucas que possibilita a inserção profissional de pessoas pouco capacitadas no mercado, o que poderia ser, em certo sentido, até uma vantagem para a economia local.

Em relação à remuneração e jornada de trabalho, o mercado de trabalho no turismo é caracterizado pelos baixos salários (Fonseca \& Petit, 2002) e por um maior número de horas semanais de trabalho (OMT, 1997). No Brasil, $67 \%$ dos ocupados formais do turismo recebem até dois salários mínimos por mês, remuneração menor do que outros setores e média da economia (Coelho \& Sakowski, 2014). Um survey on-line realizado com 215 turismólogos formados em Curitiba, PR, Brasil apontou que a maioria recebe de 1 a 3 salários mínimos por mês (Silveira \& Medaglia, 2010).

As condições de trabalho são consideradas penosas e pouco atrativas em razão das jornadas de trabalho extensas e em horários inadequados (Cunha, 1997). Em hotéis e restaurantes, por exemplo, as condições de trabalho são, frequentemente, descritas como antissociais, com expedientes de fim de semana, noturnos, irregulares em turnos divididos ou trabalho em períodos de férias (OIT, 2011). No Brasil, 89\% dos ocupados formais do turismo trabalham mais de 40 horas por semana, acima da média da economia (Coelho \& Sakowski, 2014).

A alta taxa de rotatividade é outra característica do mercado de trabalho no turismo (Arbache, 2001; Coelho \& Sakowski, 2014; OMT, 1997). As atividades turísticas, em geral, se caracterizam pela flutuação de pessoal e pelo trabalho apenas como interesse transitório (Cunha, 1997). No Brasil, 43\% dos ocupados formais do turismo estão há menos de 12 meses no emprego, o que reflete elevada rotativade (Coelho \& Sakowski, 2014). Além disso, parte expressiva dos trabalhadores em turismo situa-se no nível operacional e apenas uma ínfima parcela no nível gerencial (Paiva, 1995).

Em estudo realizado em João Pessoa (PB), Lima \& Silva (2007) mostraram que as demandas do mercado turístico não condizem com a formação oferecida pelo bacharelado em turismo, posto que as competências e habilidades elencadas pelo trade turístico não necessitam ser desenvolvidas em um curso de nível superior. Um agravante para esta situação é o fato de muitos produtos e serviços turísticos serem ofertados, em grande parte, por pequenos empreendimentos e empresários sem formação específica em turismo que acabam desconsiderando a necessidade de profissionalismo na área (Sogayar \& Rejowski, 2011).

Em suma, a Organização Internacional do Trabalho (OIT, 2011, p. 4) caracteriza o mercado de trabalho do turismo pela "predominância de empregos pontuais para satisfazer necessidades de última hora, casuais, temporários, sazonais ou de meio expediente", o que gera "situações de insegurança, salários comparativamente baixos (muitas vezes abaixo da média nacional), instabilidade no emprego, oportunidades de carreira limitadas, níveis elevados de subcontratação e terceirização e uma alta taxa de rotatividade". 
Pelo exposto, pode-se afirmar que o mercado de trabalho em turismo caracteriza-se, de modo geral, pela sazonalidade, baixa qualificação, baixa remuneração, elevada jornada de trabalho, alta rotatividade, como também pela maioria dos empregadores serem pequenas empresas, a maior oferta de empregos ser no nível operacional e haver constante desvalorização do profissional com formação superior em turismo. Conforme lembra Tomazoni (2007), o turismo possui ampla cadeia produtiva e muitas possibilidades de segmentação, mas sofre com a fragilidade em termos de oferta de emprego, sendo uma das áreas que pouco valoriza sua mão de obra.

\section{EXPECTATIVAS DO MERCADO TURÍSTICO X FORMAÇÃo SUPERIOR EM TURISMO}

O crescimento do turismo como atividade econômica que depende de mão de obra qualificada não parece estar atrelado à sua valorização e remuneração, já que os profissionais do setor não são absorvidos de forma apropriada pelo mercado de trabalho (Oganauskas et al., 2012). Lima e Silva (2007, p. 13), por exemplo, destacam que como "o mercado turístico, em sua maioria, não conhece as atribuições do Bacharel em Turismo, não sente a necessidade de possuir esse profissional nas suas organizações".

Em estudo na capital do Rio Grande do Norte, Fornari (2006) constatou que as competências desenvolvidas pelos cursos superiores de turismo atendem apenas parcialmente às exigências do mercado hoteleiro de Natal, refletindo um índice muito baixo de inserção de turismólogos no mercado de trabalho no setor hoteleiro local. Em acréscimo, um número elevado de gestores hoteleiros desconhece a formação profissional desenvolvida no ensino superior em turismo. Há, portanto, uma lacuna entre a formação esperada pelo mercado de trabalho e a realizada pelas IES, bem como entre as vagas almejadas pelos egressos e as oferecidas pelo mercado.

0 turismo abrange atividades complexas e de diversas naturezas de modo que a atuação no setor requer múltiplas formações, reunidas em um mesmo profissional (Ansarah, 2002; Tomazoni, 2007). 0 mercado costuma demandar profissionais capacitados para atuar nas diversificadas relações comerciais bem como no planejamento e gestão sustentável da atividade em todas as suas dimensões - econômica, ambiental, social, cultural e política, como se fosse possível ter múltiplas formações reunidas em um mesmo profissional (Ansarah, 2002; Tomazoni, 2007).

Ser um profissional da área do turismo tem se tornado um conceito amplo, já que pode definir diversos tipos de profissionais que se relacionam com a área, tamanha é a sua abrangência. Barretto et al. (2004) questionam se o bacharel em turismo seria mesmo esse "superprofissional" que poderia atuar tanto como garçom quanto secretário de Estado e se seria realmente possível tanta flexibilidade e polivalência. Para elas, o turismo requer diferentes profissionais para diferentes funções. Dada a diversidade de componentes da atividade turística, os cursos de turismo estariam formando pessoas para exercer centenas de funções diferentes. Essa multicapacitação excede a capacidade humana e resulta na "formação de generalistas com uma noção superficial do funcionamento do sistema e com noções superficiais de como executar algumas tarefas, o que não preenche os requisitos nem para pensar o turismo nem para prestar serviços de qualidade" (Barretto et al., 2004, p. 75). 
Partindo da premissa de que uma competência de direito garantida por um diploma pode não ser uma competência de fato, Barretto et al. (2004) entendem que se os detentores de um diploma estão habilitados para exercer determinadas funções, mas não possuem a capacitação requerida para desempenhá-las, os postos de trabalho não serão preenchidos como se espera. A esse respeito, Onzi \& Botomê (2005) questionam se os cursos de graduação em turismo estão mesmo desenvolvendo nos alunos as habilidades necessárias para atuar em um campo profissional com tais características, problematizando a ideia de que os investimentos na formação profissional impactam diretamente na inserção dos trabalhadores no mercado de trabalho.

Na visão de Yázigi,

o curso de Turismo, por si só, não se sustenta plenamente em vários tipos de atuação, razão pela qual a única saída profissionalizante desta área deve ser viabilizada por cursos de pós-graduação que ofereçam distintas possibilidades atreladas ao universo do Turismo. (2011, p. 425)

O desemprego e a divergente realidade do mercado de trabalho, encontrada pelos egressos de turismo quando findam os cursos superiores, acentuam as discussões sobre a formação profissional na área, pois retratam as contradições enfrentadas pelos profissionais em seu campo de formação.

\section{PROCEDIMENTOS METODOLÓGICOS}

Inicialmente, foi realizada uma pesquisa bibliográfica em livros e artigos científicos publicados no Brasil para fundamentar a problemática de estudo e, em seguida, foi feita uma pesquisa documental na qual foram analisados relatórios da OIT, OMT, MTUR e do Sistema de Informações sobre o Mercado de Trabalho no Setor Turismo ${ }^{2}$ (Simt) visando caracterizar o mercado de trabalho do turismo no Brasil. Posteriormente, realizou-se uma pesquisa de campo que consistiu no levantamento através de survey on-line, de natureza quantitativa e cunho descritivo. 0 instrumento de coleta de dados foi construído na plataforma Google docs, contendo dezenove perguntas fechadas e abertas.

Para atingir o universo desta pesquisa, composto por todos os turismólogos formados no território nacional, cerca de 200 mil na estimativa da Abbtur (2013), optou-se por enviar, eletronicamente, o questionário para: a) a Rede de Pesquisadores em Turismo (Repetur ${ }^{3}$ ), que reúne profissionais de todo o Brasil, solicitando aos coordenadores de curso, que dela fazem parte, encaminhar o questionário para seus egressos; b) comunidades no Facebook que englobam os bacharéis em turismo formados no país (Turismólogos e afins; Turismo - Turismólogo - Turismologia; Pesquisadores

2. O SIMT foi desenvolvido pelo Instituto de Pesquisa Econômica Aplicada (Ipea), com apoio do MTUR. Utiliza dados da Relação Anual de Informações Sociais (RAIS) e da Pesquisa Nacional por Amostra de Domicílios (PNAD). O SIMT engloba 8 das 12 atividades características do turismo (ACT) elencadas pela OMT (2011): alojamento, agências de viagem, transporte terrestre, transporte aéreo, transporte aquaviário, aluguel de transportes, alimentação e cultura e lazer.

3. Grupo virtual que inicialmente foi denominado de lista de discussão da Associação Nacional de Pesquisa e Pós-Graduação em Turismo (Anptur) cuja nomenclatura foi alterada em 29/12/13 de forma a criar um grupo de discussão sem vínculo com qualquer entidade (repetur@googlegroups.com). 
do turismo no Brasil; Turismólogos por excelência; Vida de Turismólogo; DHT-UFPE; Bacharéis em Turismo - Unifor); c) círculo de contatos dos autores.

Visando maximizar o índice de respostas, solicitou-se aos respondentes que encaminhassem o questionário aos seus contatos, utilizando, dessa forma a estratégia de bola-de-neve ${ }^{4}$. Obteve-se, assim, uma amostra não probabilística de 321 turismólogos. No tratamento dos dados foram excluídos nove casos ${ }^{5}$, assim, a amostra considerada foi composta de 312 bacharéis em turismo. Os dados foram tabulados no software SPSS e os gráficos foram gerados no Excel. A técnica de análise empregada foi a estatística descritiva.

\section{RESULTADOS E DISCUSSÃo}

Os dados obtidos na pesquisa indicaram profissionais formados em 90 instituições, sendo 19 públicas e 71 particulares. Das IES públicas, 10 são universidades federais, uma é instituto federal ${ }^{6}$, sete são universidades estaduais e uma é universidade municipal. Dentre as IES privadas, 23 são universidades, 11 são centros universitários e 37 são faculdades. Vê-se, portanto, a prevalência de bacharéis formados em instituições de ensino privadas, em concordância com o histórico de desenvolvimento do ensino superior na área.

Em se tratando de localização geográfica, as cinco regiões do país foram contempladas na amostra. As regiões Sudeste e Nordeste reuniram maior número de IES cujos egressos participaram da pesquisa, com 38,6\% e 37,5\% respectivamente, seguidas pela região Sul $(15,9 \%)$, Norte $(4,5 \%)$ e Centro-Oeste $(3,4 \%)$, com destaque para os estados de São Paulo (18,1\%), Pernambuco $(14,7 \%)$ e Bahia $(12,5 \%)$. Cabe frisar que na amostra da pesquisa, não houve registro de nenhum turismólogo formado nos seguintes estados: AM, RO, RN, MA, PI, TO e MT.

Dentre as IES citadas, as que mais tiveram egressos participando da pesquisa foram a UFPE $(14,4 \%)$, Unesp (8,3\%), USP $(7,7 \%)$, Uneb (4,2\%), Estácio da Bahia - FIB $(3,8 \%)$ e Faculdade Joaquim Nabuco (3,5\%). As demais obtiveram percentual menor do que $3 \%$ e compuseram a categoria "outras" que totalizou $58 \%$ dos participantes da pesquisa?

Quanto ao ano de conclusão do bacharelado em turismo, participaram desta pesquisa turismólogos formados desde o ano de 1980 até 2014 . Apenas $7 \%$ dos turismólogos respondentes se formaram até 1999. Na Figura 1, verifica-se crescimento do número de bacharéis formados a partir da década de 2000. Destacase o ano de 2013 que obteve maior percentual de graduados (16,7\%), seguido do ano de 2011 (10,9\%) e 2010 (9.6\%).

4. Vale salientar que como a estratégia de amostragem empregada não foi probabilística, diante da inexistência de banco de dados de turismólogos brasileiros para realização de sorteio aleatório, os resultados desta pesquisa não podem ser generalizados.

5. Os casos de número 48, 52, 149, 179, 196, 204 e 212 foram excluídos por terem grau de tecnólogo (IFAL, IFPE, IFSE e IFGO) e o caso 158, por ter feito graduação em Portugal, estando portanto fora do recorte dado pelo presente estudo que limitou-se a investigar os bacharéis formados no Brasil. Já o caso 273 foi excluído pois o respondente preencheu o questionário em duplicidade (respostas idênticas num intervalo de 1 minuto).

6. Respondente formado pelo IFGO que oferta bacharelado em turismo

7. A predominância de respondentes da Ufpe se justifica por ser a IES onde o estudo foi originado. 
Figura 1 - Conclusão do bacharelado em Turismo por década

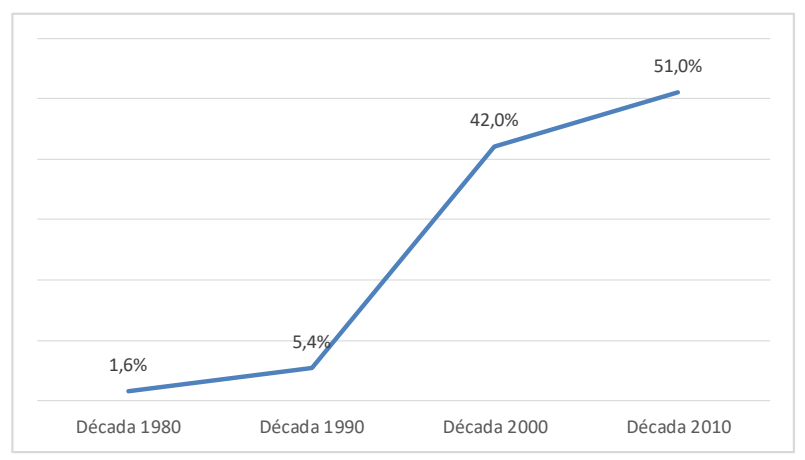

Fonte - Dados da pesquisa

Considerando que os primeiros cursos de turismo surgiram na década de 1970, vê-se que a pesquisa conseguiu incluir alguns dos primeiros bacharéis formados no país, mas que a maior parte da amostra se concentrou em profissionais formados a partir da década de 2000, período em que as IES passaram a enfrentar dificuldades para manter os cursos e que pode estar relacionado às adversidades do mercado em absorver tal mão de obra (Carvalho, 2008; Silveira et al., 2012). Como muitos se formaram nesse período, é provável que as vagas de trabalho ofertadas não tenham sido suficientes, acarretando a desvalorização da profissão.

Quanto ao gênero, constatou-se a predominância do feminino, correspondendo a $72 \%$ dos respondentes. Esse dado corrobora a Síntese do Perfil do Bacharel em Turismo cadastrado na Embratur em 1999, na qual 76,3\% eram do sexo feminino (Matias, 2002), bem como a pesquisa realizada em Curitiba, PR, Brasil na qual 73\% dos respondentes eram do sexo feminino (Silveira \& Medaglia, 2010). A predominância de mulheres não é apenas uma característica nacional já que em pesquisa realizada na Espanha (Aneca, 2005) esse percentual chega a 80\%.

Em relação à faixa etária, a maior parte dos turismólogos participantes da pesquisa possui de 20 a 30 anos, representando 61\% dos bacharéis. Verificou-se também uma porcentagem considerável dos respondentes que se encontrava na faixa entre 31 e 40 anos de idade (31\%). Ou seja, o mercado de trabalho de turismo no país é formado por jovens profissionais, conforme apresenta a Figura 2. Esse resultado corrobora dados da pesquisa de Silveira e Medaglia (2010) em Curitiba, PR, Brasil, assim como dados do Simt que apontam $67 \%$ dos ocupados formais no turismo possuindo de 25 a 49 anos (Coelho \& Sakowski, 2014).

Figura 2 - Faixa etária

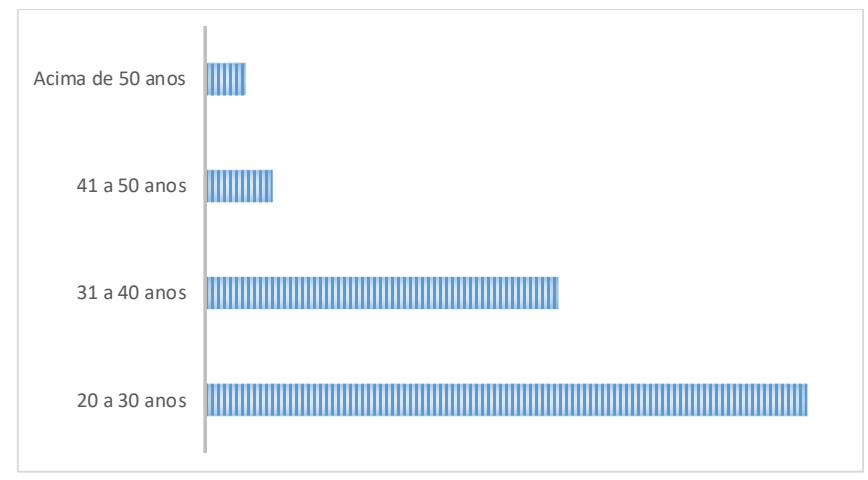

Fonte - Dados da pesquisa 
No tocante a nível de escolaridade, $46 \%$ dos turismólogos respondentes possuem apenas a graduação, o que indica que um pouco mais da metade da amostra (54\%) seguiu com os estudos em nível de pós-graduação (Figura 3), investindo em sua formação. Essa continuação dos estudos pode indicar a busca dos bacharéis por se especializar conforme as exigências do mercado, já que o curso proporciona uma formação ampla e, por vezes, generalista. Chama atenção o fato de poucos turismólogos possuírem o nível de doutorado $(4,17 \%)$ e pós-doutorado $(1,28 \%)$ já que grande parte atua na docência, como será abordado adiante.

Figura 3 - Nível de escolaridade atual

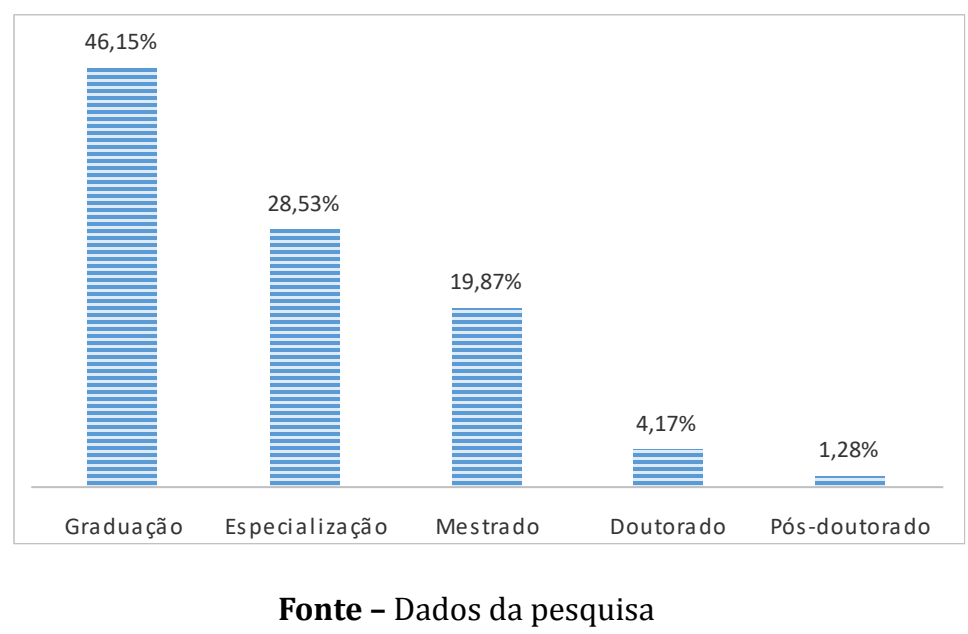

Em se tratando do conhecimento de idiomas estrangeiros, foi solicitado que os respondentes apontassem aqueles nos quais possuem fluência, grau avançado ou intermediário. Os mais citados foram inglês (86,5\%), espanhol (62,5\%) e francês $(11,85)$. Com frequência pequena, foram também citados outros idiomas $(10,57 \%)$ a saber: italiano, alemão, húngaro, tcheco, romeno, urdu, mandarim, coreano, malaio, árabe e libras. Verificou-se também que a grande maioria dos respondentes fala pelo menos um idioma e 65,7\% falam dois idiomas (Figura 4). Esses dados reforçam a importância do domínio de línguas estrangeiras para atuação no turismo, sobretudo o inglês por ser o idioma comercialmente adotado em nível mundial e o espanhol pela localização geográfica do Brasil.

Figura 4 - Idiomas falados pelos turismólogos

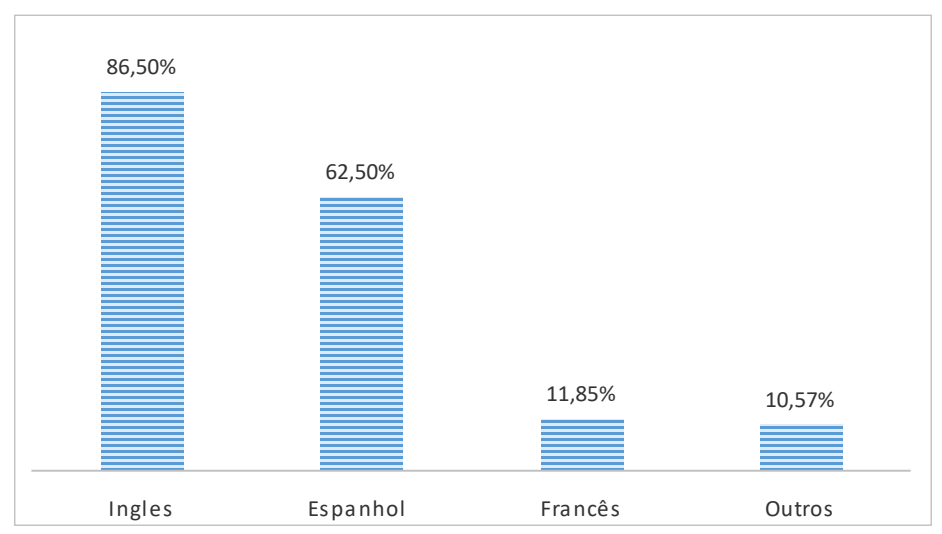

Fonte - Dados da pesquisa 
Em se tratando de experiência no exterior, 26\% dos turismólogos realizaram algum tipo de estudo em outros países, 19,2\% trabalharam fora do Brasil e $10,6 \%$ tiveram ambas experiências de estudo e trabalho no exterior. Isto reflete uma endogenia na formação, uma vez que a minoria vivenciou experiência de estudo e/ou trabalho em nível internacional.

No que se refere à atuação profissional dos turismólogos, verificou-se que $75,3 \%$ dos repondentes estavam trabalhando e $24,7 \%$ estavam desempregados no momento da pesquisa. Dos que estavam ativos, $54,8 \%$ atuavam no turismo, $19,9 \%$ não trabalhavam diretamente com a atividade turística e $25,3 \%$ não responderam, o que pode ser um indício de estarem desocupados. Esses dados corroboram estimativa da ABBTUR (2013).

Os segmentos de maior atuação dos turismólogos respondentes, apresentados na Figura 5, foram o ensino/docência com (18,6\%) e o agenciamento de viagens $(11,2 \%)$. A opção "outros" (4,5\%) reuniu áreas de atuação que obtiveram percentual menor do que 1\% englobando entidades (associações de classe e C\&VB), cruzeiros marítimos, equipamentos culturais, equipamentos de lazer, guias de turismo, jornalismo especializado em turismo, pesquisa, Organizações não Governamentais (ONG), agricultura familiar e desenvolvimento de produtos.

Figura 5 - Segmentos de atuação

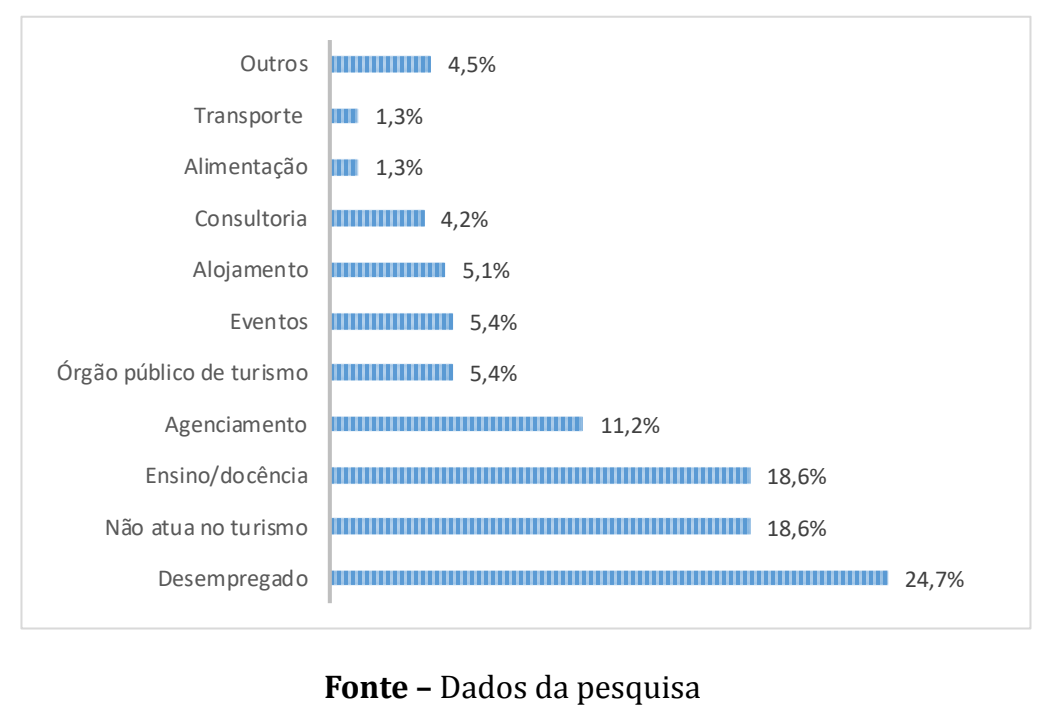

Os resultados corroboram a Síntese do Perfil do Bacharel em Turismo cadastrado na Embratur (Matias, 2002) cujas principais áreas são a educação $(21,7 \%)$, o agenciamento $(17,8 \%)$ e órgãos públicos de turismo $(15,6 \%)$. Diferentemente, os dados do Simt apontam as atividades de alimentação $(38,4 \%)$, alojamento (26\%) e transporte terrestre $(20,1 \%)$ como as que mais empregam no turismo (Coelho, 2011; Coelho \& Sakowski, 2014).

Referente ao tipo de vínculo profissional, a maioria dos turismólogos participantes desse estudo está atuando no setor privado (46\%), predominantemente como funcionário, e a minoria como autônomo e empresário. 29\% atuam no serviço público, seja como concursado ou por contrato. Percentual considerável de $25 \%$ não responderam essa questão (Figura 6), provavelmente devido ao fato de estarem desempregados, pois o percentual é próximo ao de $24,7 \%$ de desempregados no item sobre segmentos de atuação. 
Figura 6 - Vínculo profissional dos turismólogos

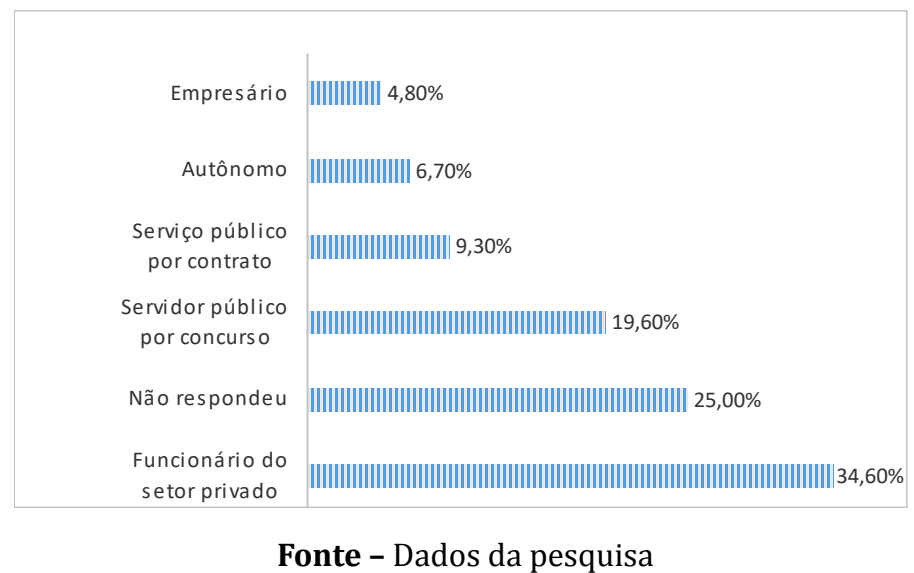

Sobre o nível do cargo que ocupam, a maior concentração de bacharéis está no primeiro nível, o operacional, com percentual de 36,9\%. Os níveis de supervisão e gerencial tiveram frequência semelhante, $13,8 \%$ e $12,2 \%$ respectivamente. Apenas 8,3\% ocupam cargo em nível de chefia e de direção. Chamou atenção o fato de $28,8 \%$ dos respondentes terem deixado essa questão em branco (Figura 7), semelhante ao tópico anterior. Esses resultados ratificam as discussões encontradas na literatura sobre a subocupação dos bacharéis em cargos de nível operacional, para os quais não seriam necessários os conhecimentos adquiridos no decorrer da graduação.

Figura 7 - Nível do cargo

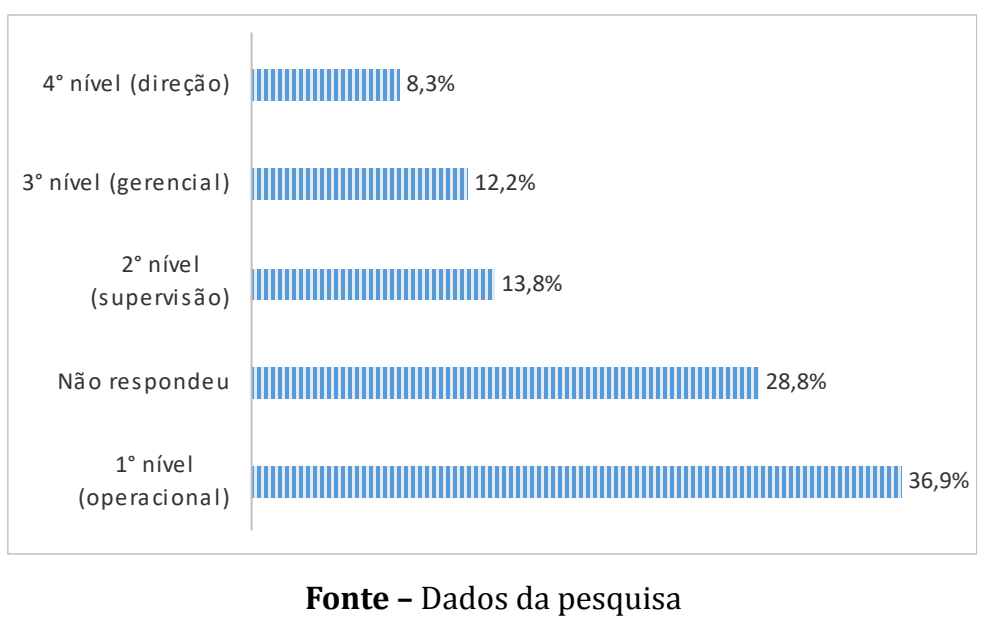

Quase a totalidade dos bacharéis em turismo formados no Brasil estavam atuando profissionalmente no país. Houve apenas um único registro de profissional atuando no exterior, especificamente em Santiago no Chile. Verificou-se ainda pequena mobilidade entre regiões onde os turismólogos se formaram e onde atuam profissionalmente, conforme indica a Figura 8, na qual a primeira coluna corresponde à região de formação e a segunda ao local no qual a pessoa está atuando profissionalmente, no momento da pesquisa.

A mesma situação de baixa mobilidade também foi detectada em nível estadual. Os três estados que se destacaram na amostra com maior número de bacharéis formados também foram os mesmos onde a maioria trabalha: Pernambuco, São Paulo e Bahia. Com menor frequência, destacaram-se Minas Gerais, Rio de Janeiro e Rio Grande do Sul. 0 mesmo parece ocorrer em nível municipal. A pesquisa feita por Silveira \& 
Medaglia (2010) em Curitiba, PR, Brasil revelou que poucos turismólogos saíram da cidade depois de formados. 0 percentual de curitibanos que permaneceu na capital após a colação de grau foi de 89\%, o que pode indicar que esses locais de formação conseguem manter os seus profissionais, oferecendo-lhes oportunidades de atuação.

Figura 8 - Região de formação e atuação dos turismólogos

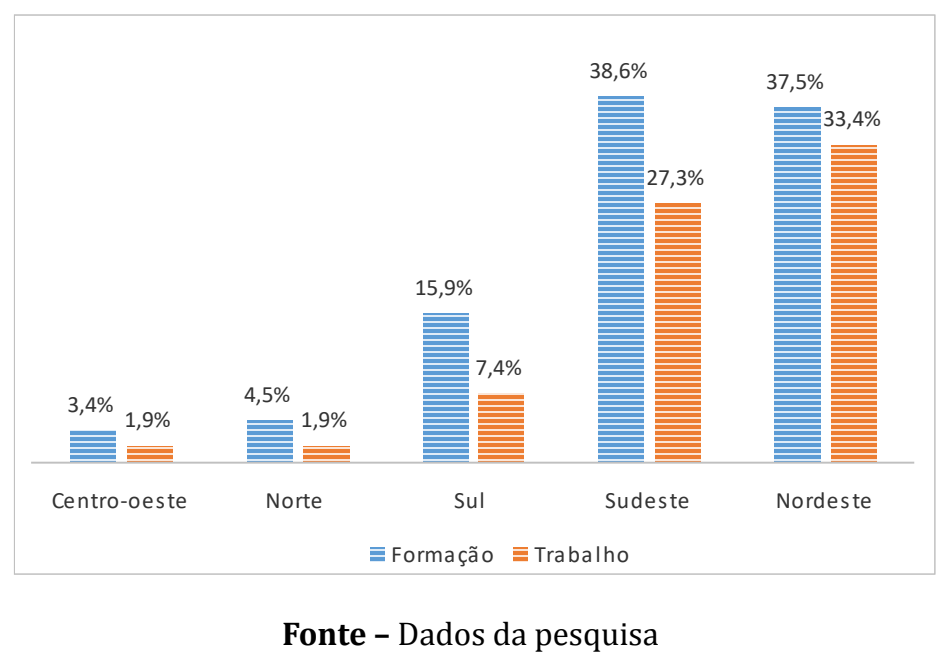

Os postos de trabalho ocupados pelos participantes encontram-se, em sua maioria, em capitais (51,1\%), provavelmente em função da maior oferta de empregos de modo geral e da oferta de cursos também. A minoria trabalha em cidades do interior (21,2\%), o que pode estar relacionado a cidades litorâneas ou de campo, nas quais há, com frequência, oferta de postos de trabalho no turismo. Mais uma vez, cabe enfatizar o percentual de não respostas à questão de local de trabalho $(27,7 \%)$.

Sobre a remuneração mensal, 36,5\% dos turismólogos afirmaram receber entre um e dois salários mínimos, o que pode ser considerada uma baixa remuneração, principalmente quando relacionada à carga horária de trabalho e ao grau de formação dos profissionais (Figura 9). Segundo dados do Simt (2015), a baixa remuneração é a realidade de $67 \%$ dos ocupados formais em turismo que recebem até dois salários mínimos mensais. Esse dado também está em concordância com as informações encontradas na literatura e nessa pesquisa, reforçando tal realidade.

Figura 9 - Remuneração mensal

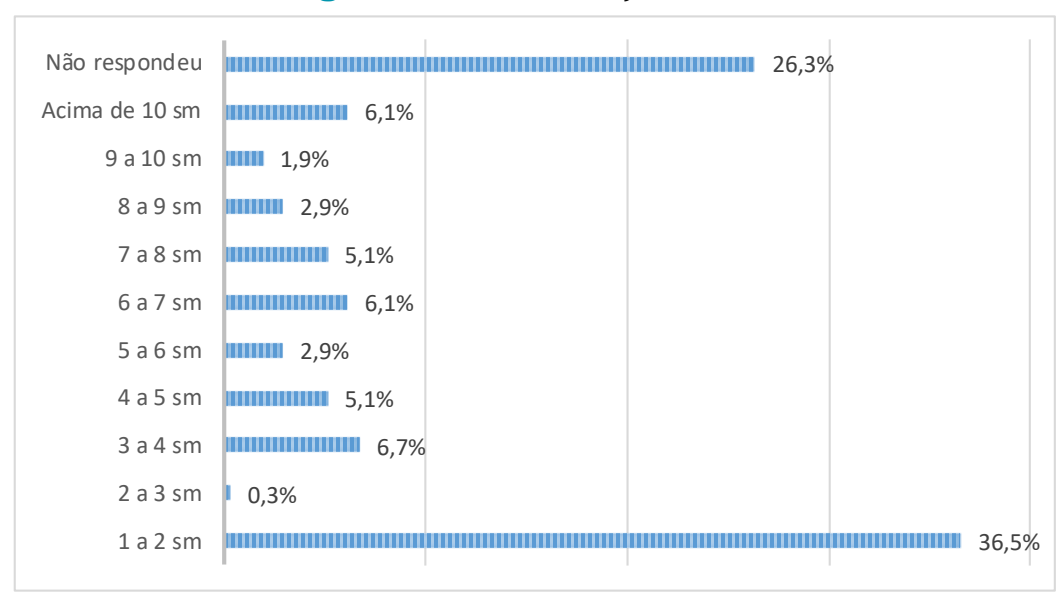

Fonte - Dados da pesquisa 
Em se tratando do enfrentamento de algum tipo de dificuldade para entrar no mercado de trabalho após a conclusão do curso, as respostas dos bacharéis em turismo foram divididas: 49,7\% dos participantes afirmaram que sim, e 50,3\% que não. Da metade que declarou não ter dificuldades, $27 \%$ já estavam trabalhando antes mesmo de concluir o curso. 0 fato dos estudantes realizarem estágios durante a graduação pode contribuir para minimizar as dificuldades de inserção no mercado de trabalho, já que possibilita a obtenção de experiência profissional ainda durante o curso. Esse resultado corrobora a pesquisa de Silveira \& Medaglia (2010) que apontou que 43\% dos turismólogos formados em Curitiba, PR, Brasil já estavam trabalhando na área de turismo quando concluíram seus cursos, remetendo assim à importância do estágio e à opção por capacitação superior de profissionais já empregados.

Os turismólogos que alegaram ter encontrado dificuldades em se inserir no mercado de trabalho utilizaram como justificativa, em sua maioria, a remuneração inadequada das vagas (32\%) e as poucas vagas ofertadas pelo mercado de trabalho (22\%). Alegaram também o fato dos postos de trabalho ofertados não condizerem com a formação obtida (15\%) e a falta de experiência anterior (12\%), como apresentado na Figura 10.

Figura 10 - Principais dificuldades para inserção no mercado de trabalho

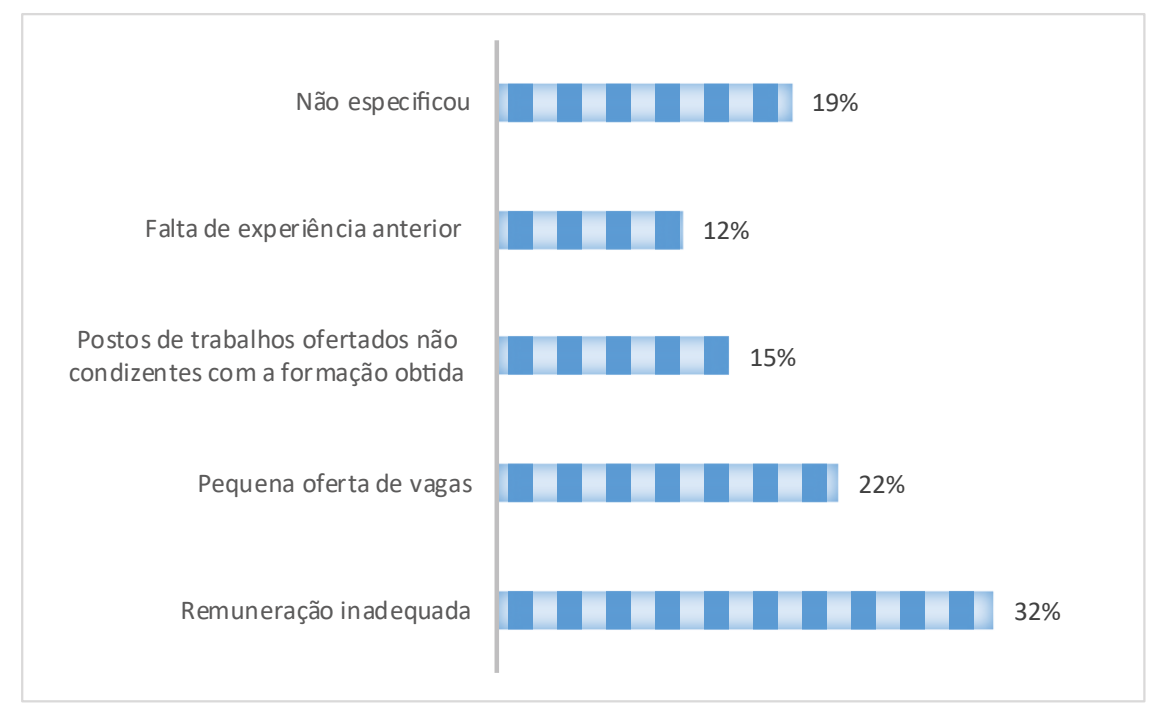

Fonte - Dados da pesquisa

A remuneração inadequada das vagas expressa a insatisfação dos bacharéis quanto ao retorno financeiro que o mercado propõe para o seu trabalho, considerado baixo (Coelho \& Sakowski, 2014; Fonseca \& Petit, 2002). Ao mesmo tempo, a percepção de que existem poucas vagas sendo ofertadas na área alerta para a quantidade de profissionais formados em detrimento da capacidade de absorção de mão de obra na atividade. Já a informação de que os postos de trabalhos oferecidos não condizem com a formação obtida, sinaliza a distância existente entre a formação acadêmica e a preparação para o mercado de trabalho, problemática discutida recorrentemente na literatura da área em estudo (Ansarah, 2002; Barretto et al., 2004; Fornari, 2006; Lima \& Silva, 2007; Tomazoni, 2007).

Sobre o grau de importância do bacharelado em turismo para a atuação no mercado de trabalho, cabe ressaltar que a maioria qualificou o curso como muito importante $(41,3 \%)$ e importante $(30,4 \%)$. Uma minoria $(8,3 \%)$, apenas, considera o curso 
sem importância para sua prática profissional, como demonstra a Figura 11. Nesse sentido, a qualificação proporcionada pelo curso e a relação desta com o mercado de trabalho foram vistas de forma positiva pela grande maioria dos respondentes.

Figura 11 - Grau de importância do bacharelado em turismo para atuação no mercado de trabalho

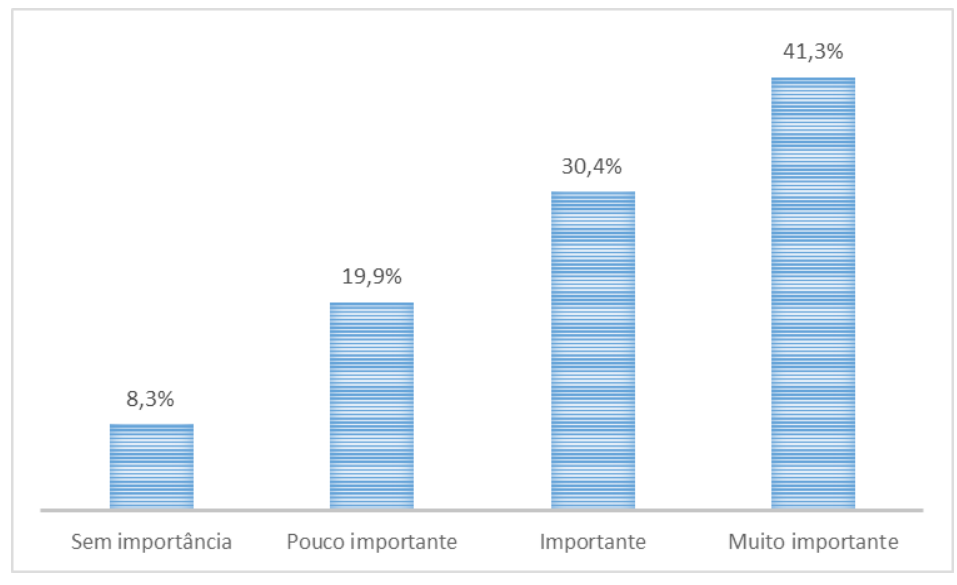

Fonte - Dados da pesquisa

Por fim, os bacharéis foram solicitados a expressar a sua satisfação em relação à atuação no mercado de trabalho. A esse respeito, a maioria dos respondentes se dividiu entre satisfeitos $(35,9 \%)$ e pouco satisfeitos $(31,1 \%)$, havendo ainda o mesmo percentual de bacharéis que opinaram de modo extremamente oposto: $16,3 \%$ afirmaram que estavam muito satisfeitos e 16,3\% insatisfeitos (Figura 12). Pesquisa realizada em Curitiba, PR, Brasil revelou que a maioria dos turismólogos se manteve no nível intermediário de satisfação, com tendência ao positivo (Silveira \& Medaglia, 2010).

Figura 12 - Satisfação em relação à atuação no mercado de trabalho

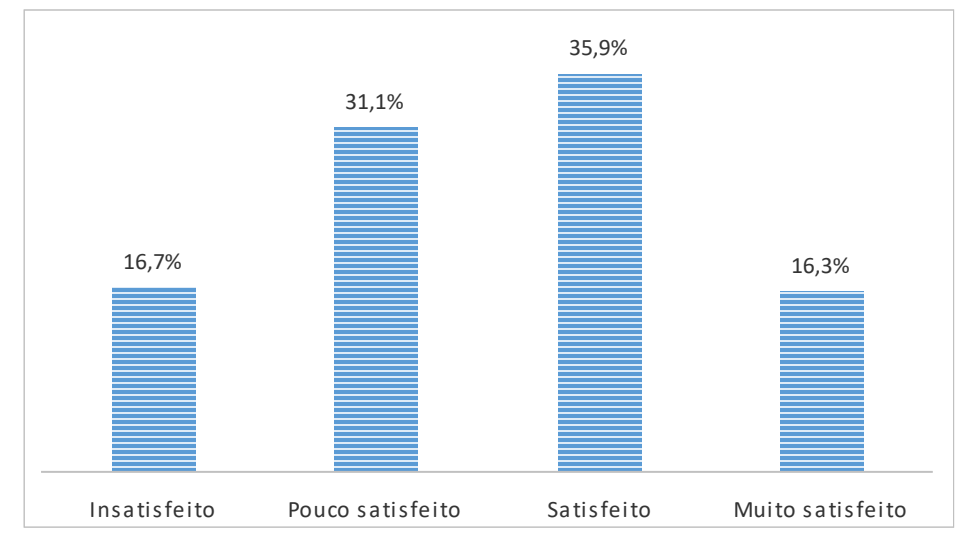

Fonte - Dados da pesquisa

As justificativas para o grau de satisfação atribuído pelos respondentes foram variadas. Merece destaque a diversidade de opções de atuação no campo do turismo e o amor pela profissão, como apontado pelo Respondente 96: "Vejo muitas oportunidades no ramo de turismo, estou aprendendo cada dia mais. Amo minha profissão!" Verificou-se que mesmo os profissionais satisfeitos com sua atuação no mercado de trabalho percebem que não é uma área de fácil inserção e revelam descontentamento com relação aos salários e ao não reconhecimento da profissão: "Apesar de estar muito satisfeita com minha carreira, creio que sou exceção e sei como o mercado paga 
mal e não faz a seleção de pessoas corretamente em muitos casos". (Respondente 54). Nessa mesma perspectiva, a Respondente 303 argumentou o seguinte:

Estou muito satisfeita com a minha atuação no mercado de trabalho, acredito que minha formação colaborou muito para que me tornasse a profissional que sou, porém ainda acho que falta um pouco de valorização do profissional do turismo. Ainda recebemos pouco e trabalhamos muito e muitas vezes vemos pessoas que não são da área atuar em nossos lugares.

A remuneração é uma questão crucial posto que “o retorno financeiro da prestação de um serviço é a condição básica para a sobrevivência pessoal e o indicador de sucesso dos esforços individuais" (Ansarah, 1995, p. 61). Dentre os comentários que demonstram insatisfação, o Respondente 243 ressalta que "Trabalha-se muito e a remuneração não segue a mesma linha". A baixa remuneração foi associada à falta de valorização profissional por alguns respondentes:

Ganho pouco, trabalho muito e não tenho meu trabalho valorizado. Concluí a graduação em Turismo objetivando atuar na área de planejamento, inclusive, buscando me especializar nela. Contudo, tive muita dificuldade em ingressar no ramo almejado, por conta disso, busquei a hotelaria, mesmo não me identificando com ela! (Respondente 217)

Passei os quatro anos do meu curso, ouvindo de todos os professores que o turismólogo existe para planejar, gerir e executar as atividades turísticas em todos os seus aspectos. A realidade se mostra muito diferente da teoria. A maioria dos cargos oferecidos para os profissionais da área são operacionais: Trabalhar no operacional ou comercial de eventos de um hotel; ser um agente de viagens; um agente de aeroporto... Enquanto administradores tornam-se gerentes dos hotéis; os profissionais de marketing, os criadores dos eventos... Os cargos em entidades turísticas - Abav, Conventions, etc, em sua maioria são por indicação; Concursos na área são quase extintos. A menos que se tenha capital para ser um empreendedor de algum negócio na área, hoje não aconselho mais ninguém a ser tornar turismólogos. (Respondente 39)

Esses comentários destacam ainda mais a baixa remuneração no turismo e relevam a busca por outras áreas de atuação e até mesmo outras graduações por parte dos formados. Sobre esse quesito de insatisfação, vale destacar ainda, que os turismólogos citaram o jogo político necessário para alcançar cargos de planejamento público na atividade como algo negativo na área, fato que pode ressaltar a desvalorização do profissional perante o poder público.

\section{CONSIDERAÇÕES FINAIS}

Analisar carreiras e profissões no turismo pressupõe entender as características do seu mercado de trabalho, a natureza dos empregos e as dimensões dessa indústria, como postula Ladkin (2008). Neste contexto, compreende-se que o problema de contratação dos turismólogos no mercado de trabalho, não é apenas um problema nacional. Dados da Austrália, Reino Unido (Barretto et al., 2004) e Espanha (Aneca, 2005) indicam baixo índice de empregabilidade dos profissionais. 
Os resultados dessa pesquisa no Brasil apontam uma realidade compatível com o cenário internacional. Obteve-se um perfil predominante de turismólogos do gênero feminino, com idade entre 20 e 30 anos, nível de escolaridade de graduação, domínio de inglês e/ou o espanhol, sem experiência de estudo ou trabalho no exterior e atuando diretamente na área do turismo. Os segmentos de maior atuação são o ensino/docência e agenciamento de viagens, com vínculo de funcionário do setor privado ou servidor público por concurso, ocupando cargos de nível operacional. A maior parte dos respondentes recebe entre um a dois salários mínimos. A metade que enfrentou dificuldade para entrar no mercado de trabalho após a conclusão do curso se queixou da remuneração inadequada e da pequena oferta de vagas pelo mercado de trabalho. A maioria dos respondentes se definiu como satisfeita e pouco satisfeita em relação a sua atuação no mercado de trabalho.

Embora o panorama traçado refira-se apenas à amostra obtida, que por não ser do tipo probabilística não pode ter seus resultados generalizados aos turismólogos brasileiros, algumas questões levantadas nesta pesquisa merecem reflexão. A baixa remuneração dos profissionais e o pequeno número de profissionais autônomos ou empresários ressaltam a necessidade de ampliar os incentivos e a preparação para o empreendedorismo, inclusive como saída para as poucas vagas ofertadas pelo mercado para os profissionais de nível superior.

A busca por diferentes áreas de atuação e até mesmo outras graduações por parte dos bacharéis pode indicar a importância da especialização e da aquisição de conhecimentos em áreas específicas, que não são adquiridos na graduação. E o diálogo constante entre instituições de ensino e mercado, assim como a realização de estágios por parte dos graduandos são pontos que podem minimizar os desafios e proporcionar a criação de vínculos com o mercado turístico (Busby, 2008).

Conforme indicado pela academia e verificado nesta pesquisa, a desvalorização do profissional bacharel em turismo, os baixos salários, os cargos estritamente operacionais e a pouca oferta de vagas são pontos que marcam o cenário do mercado de trabalho turístico no país. Por outro lado, as contradições existentes no ensino superior de turismo não se mostraram tão presentes nesse contexto, visto que a maioria dos respondentes definiu o bacharelado em turismo como importante e/ou muito importante para a sua atuação no mercado de trabalho.

Espera-se, com este estudo, sinalizar a situação dos turismólogos diante do mercado de trabalho, elucidando desafios tanto para estudantes e profissionais quanto para as IES formadoras. Em termos de sugestões para futuras pesquisas, endossa-se a recomendação de Tomazoni (2007) de analisar a empregabilidade por cada segmento turístico de acordo com critérios próprios e específicos, uma vez que a empregabilidade em hotelaria, eventos e agenciamento, por exemplo, podem ser completamente distintas. Outras pesquisas também podem ser feitas no intuito de acompanhar o desenvolvimento do mercado de trabalho no turismo e, assim, perceber de que forma é possível agir em busca de melhorias para a atuação do seus profissionais.

\section{REFERÊNCIAS}

Agencia Nacional de Evaluación de la Calidad y Acreditación. (2005). Libro blanco: Título de grado en turismo. Madrid, España: Aneca. 
Ansarah, M. G. R. (1995). Educação e formação do bacharel em Turismo. Turismo em Análise, 6(1), 43-64.

Ansarah, M. G. R. (2002). Formação e capacitação do profissional em Turismo e hotelaria: Reflexões e cadastro das instituições educacionais no Brasil. São Paulo, SP: Aleph.

Arbache, J. S. (2001). O mercado de trabalho na atividade econômica do turismo no Brasil. Brasília, DF: UnB.

Associação Brasileira de Turismólogos e Profissionais do Turismo. (2013). ABBTUR luta pelo turismólogo no código brasileiro de ocupações - CBO. Rio de Janeiro, RJ: ABBTUR. Recuperado de https://bit.ly/2Y829Rh

Barretto, M., Tamanini, E., \& Silva, M. I. P. (2004). Discutindo o ensino universitário de Turismo. Campinas, SP: Papirus.

Busby, G. (2008). Experiência de trabalho e vínculos com a indústria. In D. Airey \& J. Tribe (Orgs.), Educação internacional em Turismo (pp. 135-156). São Paulo, SP: Senac.

Carvalho, M. A. (2008). Os números do ensino superior em turismo e hospitalidade no Brasil: 2001 a 2006. In Anais do 5o Seminário da Associação Nacional de Pesquisa e PósGraduação em Turismo, 2008, Belo Horizonte, MG. São Paulo: Anptur.

Coelho, M. H.P. (2011). Ocupação do setor de turismo no Brasil: Análise da ocupação nas principais ACTS nos estados, regiões e Brasil. Brasília, DF: Ipea. Recuperado de https://bit.ly/2yb0DhN

Coelho, M. H. P., \& Sakowski, P. A. M. (2014). Perfil da mão de obra do turismo no Brasil nas atividades características do turismo e em ocupações. Brasília, DF: Ipea. Recuperado de https://bit.ly/2K0Efx4

Costa, J. H. (2008). Políticas públicas, turismo e emprego no litoral potiguar. Caderno Virtual de Turismo, 8(2), 115-129.

Cunha, L. (1997). Economia e política do turismo. Lisboa, Portugal: McGraw-Hill.

Fonseca, M. A. P., \& Petit, A. (2002). Turismo e trabalho em áreas periféricas. Scripta Nova, Revista Eletrónica de Geografia y Ciencias Sociales, 6(119), 128.

Fornari, I. S. (2006). Educação superior em turismo: o profissional de turismo frente às competências exigidas pelo mercado de trabalho do setor hoteleiro em Natal. Dissertação de Mestrado, Centro de Ciências Sociais Aplicadas, Universidade Federal do Rio Grande do Norte, Natal.

Instituto Brasileiro de Geografia e Estatística. (2012). Economia do turismo: Uma perspectiva macroeconômica 2003-2009. Rio de Janeiro, RJ: IBGE.

Kong, A. P. (2015). The dilemma facing higher education and industry in tourism and hospitality. SpringerPlus, 4(suppl 2), 2.

Ladkin, A. (2008). Carreiras profissionais e emprego. In D. Airey \& J. Tribe (Orgs.), Educação Internacional em Turismo (pp. 589-608). São Paulo, SP: Senac.

Leal, S. R., Panosso Netto, A., \& Trigo, L. G. G. (2012). Tourism education and research in Brazil. In G. Lohmann \& D. Dredge (Orgs.), Tourism in Brazil: Environment, management and segments (pp. 173-188). Abingdon, United Kingdom: Routledge.

Lima, A. V. B., \& Silva, S. D. C. M. (2007). Bacharel em turismo: profissional sem formação de mercado ou mercado sem conhecimento da profissão? In Anais do 4⿳o Seminário da Associação Brasileira de Pesquisa e Pós-Graduação em Turismo, 2007, São Paulo, SP. São Paulo, SP: Anptur.

Matias, M. (2002). Turismo formação e profissionalização: 30 anos de história. São Paulo, SP: Manole.

Matias, K. C. O., \& Costa, M. S. (2010). Políticas públicas para a geração de empregos: considerações sobre o Proger Turismo. Revista Turismo Visão e Ação, 12(1), 73-91.

Mota, K. C. N., \& Anjos, F. A. (2012). Educação superior em turismo no Brasil: análise da oferta de cursos superiores no Nordeste brasileiro pelos institutos federais. Revista Brasileira de Pesquisa em Turismo, 6(1), 48-63. 
Oganauskas, D. S. N., Gomes, B. M. A., \& Andrukiu, A. M. G. (2012). Bacharelado em Turismo no Brasil: história e contribuições da Universidade Federal do Paraná. Turismo \& Sociedade, 5(2), 563-583.

Onzi, L., \& Botomé, S. P. (2005). Características do ensino superior de graduação em Turismo: a organização do conhecimento como critério de planejamento da formação profissional. Turismo em Análise, 16(2), 133-156.

Organização Internacional do Trabalho. (2011). Manual para a redução da pobreza por meio do turismo. Genebra, Suíça: OIT. Recuperado de https://bit.ly/20pElnq

Organização Mundial do Turismo. (1997). Introducción a TEDQUAL: una metodología para la calidad en educación y formación turísticas. Madrid, MD: OMT.

Organização Mundial do Turismo. (2011). International recommendations on tourism statistics 2008. Draft compilation guide. Madrid, España: OMT. Recuperado de https://bit.ly/2Y8ecOv

Paiva, M. G. M. V. (1995). Sociologia do turismo. Campinas, SP: Papirus.

Silveira, C. E., \& Medaglia, J. (2010). Reflexões sobre a atuação profissional dos turismólogos e o planejamento do turismo: pesquisa com os egressos dos cursos de Turismo de Curitiba, Paraná, Brasil. Revista Turismo \& Sociedade, 3(2), 123-146.

Silveira, C. E., Medaglia, J., \& Gândara, J. M. G. (2012). Quatro décadas de ensino superior de turismo no Brasil: dificuldades na formação e consolidação do mercado de trabalho e a ascensão de uma área de estudo como efeito colateral. Revista Turismo Visão e Ação, 14(1), 6-18.

Sogayar, R. L., \& Rejowski, M. (2011). Ensino superior em Turismo em busca de novos paradigmas educacionais: problemas, desafios e forças de pressão. Revista Turismo Visão e Ação, 13(3), 282-298.

Tomazoni, E. L. (2007). Educação profissional em turismo: cria-se mercado pela formação? Revista Turismo em Análise, 18(2), 197-219.

Yázigi, E. (2011). Por um novo horizonte profissional do turismólogo. Rosa dos Ventos, $3(3), 424-432$.

World Travel \& Tourism Council. (2017). Travel \& tourism economic impact 2017: Brazil. London, United Kingdom: WTTC.

Recebido em: $17 / 7 / 2017$

Aprovado em: 30/07/2017

\section{CONTRIBUIÇÕES}

Luana Alexandre Silva: Definição do problema de pesquisa e objetivos, desenvolvimento da proposição teórica, realização da revisão bibliográfica e fundamentação teórica, coleta de dados, análise de dados, elaboração de tabelas, gráficos e figuras, redação do manuscrito, adequação do manuscrito às normas da RTA.

Luciana Araújo de Holanda: Definição do problema de pesquisa e objetivos, desenvolvimento da proposição teórica, escolha dos procedimentos metodológicos, análise de dados, revisão crítica do manuscrito, adequação do manuscrito às normas da RTA.

Sérgio Rodrigues Leal: Revisão crítica do manuscrito; redação do manuscrito. 